\title{
Pengalaman Spiritualitas pada Pasien Penyakit Ginjal Kronik yang Menjalani Hemodialisis
}

\author{
Fitri Mailani, Setiawan, Cholina T. S \\ Fakultas Keperawatan Universitas Sumatera Utara \\ E-mail:fitri_maillani@yahoo.com
}

\begin{abstract}
Abstrak
Spiritualitas merupakan aspek yang sangat penting bagi pasien yang menderita penyakit ginjal kronik yang menjalani hemodialisis. Tujuan penelitian ini adalah untuk mengeksplorasi spiritualitas pasien penyakit ginjal kronik yang menjalani hemodialisis. Penelitian ini merupakan studi fenomenologi deskriptif. Metode pengumpulan data dilakukan dengan wawancara mendalam. Partisipan dalam penelitian ini berjumlah 10 orang yang berasal dari unit hemodialisis RSUP H.Adam Malik dan RSU dr. Pirngadi Medan dengan kriteria partisipan berusia lebih dari 18 tahun, menjalani hemodialisis lebih dari 3 bulan, kesadaran compos mentis dan reguler menjalani hemodialisa 2 kali seminggu. Data yang diperoleh dianalisis dengan pendekatan Colaizzi. Dari hasil analisis penelitian di temukan 4 tema yang mencerminkan fenomena yang diteliti. Tema-tema tersebut antara lain adalah mendekatkan diri kepada Tuhan, dukungan dari orang terdekat, mempunyai harapan besar untuk sembuh, dan menerima dengan ikhlas penyakit yang diderita. Dengan demikian disarankan kepada perawat dialisis untuk membuat program yang mendukung kegiatan spiritualitas secara berkelompok sesuai dengan kepercayaan masing-masing pasien.
\end{abstract}

Kata kunci: Hemodialisis, penyakit ginjal kronik, spiritualitas.

\section{Spiritual Experience of Chronic Renal Failure Patient Undergoing Hemodialysis}

\begin{abstract}
Spirituality is a very important issue in patients with chronic renal failure undergoing hemodialysis. The purpose of this qualitative study was to explore the spirituality experience of patients with chronic renal failure undergoing hemodialysis. The design of this study is phenomenology. Data were collected through in-depth interviews that conducted with 10 participants selected from renal unit of RSUP. H. Adam Malik and RSUD dr. Pirngadi Medan hospital based on criteria including age more than 18 years old, undergoing hemodialysis more than 3 months, composmentis and reguler hemodialysis 2 times a week. The collected data were analyzed using Colaizzi apporach to analysis. The results of this study showed four including being closer to God, the support of the people nearby, had great hopes for recovery, and willingly accept the illness. This study suggested the dialysis nurses to create program to support spiritual activity.
\end{abstract}

Key words: Chronic kidney disease, hemodialysis, spirituality. 
Fitri Mailani: Pengalaman Spiritualitas pada Pasien Penyakit Ginjal Kronis

\section{Pendahuluan}

Penyakit ginjal kronik adalah kerusakan ginjal yang menyebabkan ginjal tidak dapat membuang racun dan produk sisa dari darah (Black \& Hawks, 2009). Indonesia termasuk negara dengan tingkat penderita penyakit ginjal kronik yang cukup tinggi, data dari ASKES tahun 2010 tercatat 17.507 pasien, tahun berikutnya tercatat 23.261 dan data terakhir tahun 2013 tercatat 24.141 orang pasien (Namawi, 2013). Hemodialisis (HD) merupakan suatu proses terapi pengganti ginjal yang berfungsi mengoreksi gangguan keseimbangan cairan dan elektrolit pada pasien gagal ginjal (Ignatavicius \& Workman, 2009), meskipun begitu pasien gagal ginjal tetap akan merasakan berbagai keluhan akibat gagal ginjal kronik yang dialaminya yaitu masalah hematologi, nutrisi, endokrin, muskuloskeletal, dan respon imun yang abnormal. Perawat yang bertugas di ruang hemodialisa merupakan tenaga medis yang mendampingi pasien selama proses HD dilaksanakan, untuk itu perawat dialisis dituntut untuk memberikan memberi asuhan secara holistik, meliputi upaya mengembalikan kesehatan fisik, emosi, spiritual dan sosial (Headley \& Wall, 2000).

Gagal ginjal kronik merupakan salah satu penyakit terminal yang akan mempengaruhi kualitas hidup pasien termasuk masalah spiritualitas. Model holistik mengatakan bahwa semua penyakit yang memiliki komponen psikosomatik, dan biologis, faktor psikologis, sosial, dan spiritual selalu berkontribusi dalam gejala- gejala penyakitnya Dimensi spiritual dalam model bio-psiko-sosial-spiritual menggabungkan spiritual dalam konteks yang lebih luas yaitu nilai-nilai, makna dan tujuan hidup (Dossey, 2005).

Sebagai perawat yang bertugas di ruang hemodialisa diharapkan mampu memanfaatkan kekuatan spiritualitas, merawat kesehatan fisik, pikiran, dan jiwa, serta berusaha untuk menciptakan kondisi budaya organisasi yang menumbuhkan spiritualitas (Headley \& Wall, 2000). Sebagai langkah utama mengupayakan penyembuhan adalah menciptakan lingkungan yang berusaha memahami spiritualitas yang nantinya akan mempengaruhi kehidupan pasien yang menjalani hemodialisis (Walton, J., 2007). Spiritualitas mengandung pengertian hubungan manusia dengan Tuhannya dengan menggunakan medium sholat, puasa, zakat, haji, doa dan sebagainya (Hawari, 2002 ). Selain itu, komponen spiritualitas juga terdiri dari hubungan manusia dengan alam, hubungan dengan dirinya sendiri dan hubungan dengan orang lain (Dossey, 2005).

Banyak peneliti juga berpendapat bahwa masalah spiritual merupakan masalah yang sangat penting bagi pasien yang menderita penyakit kronik yang mengancam jiwa, untuk itu perlu pendekatan dengan model biopsikososial-spiritual dalam merawat pasien (Bele, Bodhare, Mudgalkan, Saraf, \& Valsangkar, 2012). Gangguan spiritualitas akan menyebabkan gangguan berat secara psikologis termasuk keinginan bunuh diri (Bele, dkk, 2012). Untuk itu perlu dilakukan pendekatan secara spiritual dalam meningkatkan kualitas hidup pasien penyakit ginjal kronik yang menjalani hemodialisis baik dari keluarga maupun tenaga medis yang mendampingi pasien dalam menjalani proses hemodialisis. Penelitian ini dilakukan dengan pendekatan fenomenologi karena ingin menggali kondisi spiritualitas pasien yang menjalani hemodialisis. Selain itu, dengan menggunakan pendekatan fenomenologi akan diperoleh informasi baru yang lebih banyak dan komprehensif serta mendalam terkait spiritualitas pada pasien.

\section{Metode Penelitian}

Jenis penelitian yang dilakukan adalah fenomenologi deskriptif. Fenomenologi deskriptif merupakan desain penelitian yang melibatkan eksplorasi langsung, analisa data dan deskripsi dari fenomena tertentu, sebebas mungkin dari dugaan yang belum teruji, yang bertujuan mendapatkan hasil yang maksimal dari pengalaman individu tentang 'sesuatu' baik yang dilihat, dirasakan, diingat, Lippincot dipercayai, diputuskan, dilakukan dan seterusnya (Streubert \& Carpenter, 2011). Partisipan dalam penelitian ini berjumlah 10 orang yang berasal dari RSUD dr. Pirngadi dan RSUP Haji Adam Malik Medan yang diambil dengan metode purposive sampling. 
Fitri Mailani: Pengalaman Spiritualitas pada Pasien Penyakit Ginjal Kronis

Partisipan yang terlibat pada penelitian ini harus memenuhi kriteria inklusi sebagai berikut :

a. Berusia lebih dari 18 tahun

b. Menjalani terapi hemodialisis regular 2 kali perminggu

c. $\quad$ Kesadaran compos mentis

d. Sudah mengikuti hemodialisis lebih dari 3 bulan

Penelitian dimulai dengan memberikan kuesioner data demografi dan dilanjutkan dengan wawancara mendalam (in-depth interview) tentang makna spiritualitas bagi parisipan. Wawancara dilakukan oleh peneliti dengan durasi 30-60 menit dan alat yang digunakan untuk merekam wawancara adalah tape recorder. Tingkat keabsahan data yang dilakukan pada penelitian adalah credibility, dependability, transferability, dan confirmability (Lincoln dan Guba, 2005).

Peneliti melakukan analisis data menggunakan pendekatan dari Colaizzi (1978, dalam Speziale \& Carpenter, 2003). Tahapan metode analisis data dengan langkah-langkah antara lain: (1) Membaca dan menyalin seluruh deskripsi wawancara yang telah diungkapkan oleh partisipan, (2) Melakukan ekstraksi terhadap pernyataan signifikan (pernyataan yang secara langsung berhubungan dengan fenomena yang diteliti), (3) Menguraikan makna yang terkandung dalam pernyataan signifikan, (4) Menggabungkan makna yang dirumuskan ke dalam kelompok tema, (5) Mengembangkan sebuah deskripsi tema dengan lengkap (yaitu deskripsi yang komprehensif dari pengalaman yang diungkapkan partisipan), (6) Mengidentifikasi landasan struktur dari fenomena tersebut, dan (7) Kembali ke partisipan untuk melakukan validasi. Peneliti melakukan penelitian setelah mendapatkan persetujuan etik (ethical clearence) dari komite etik penelitian kesehatan dari Fakultas Keperawatan Universitas Sumatera Utara (F.Kep-USU) dan mendapatkan izin dari rumah sakit dan staf keperawatan yang bekerja di unit hemodialisis.

\section{Hasil Penelitian}

Karakteristik partisipan berusia rentang 26 -59 tahun, mayoritas berjenis kelamin laki- laki sebanyak 6 orang. Lama menjalani hemodialisis dari rentang 4 bulan sampai 10 tahun dan mayoritas lebih dari 1 tahun. Mayoritas partisipan beragama islam dan bersuku batak. Rentang tingkat pendidikan bervariasi mulai tamat SMP sampai dengan perguruan tinggi dan seluruh partisipan telah menikah.

Hasil analisa data kualitatif dengan wawancara mendalam didapatkan empat tema spiritualitas pada pasien penyakit ginjal kronik yang menjalani hemodialisis yaitu: 1) mendekatkan diri kepada Tuhan, 2) dukungan dari orang terdekat, 3) mempunyai harapan besar untuk sembuh, dan 4) menerima dengan ikhlas penyakit yang diderita.

Hal yang dirasakan oleh sebagian besar partisipan dalam kehidupan spiritualnya adalah mendekatkan diri kepada Tuhan, seperti dengan rajin beribadah, memperdalam ilmu agama, dan memperbaiki kualitas ibadah dalam kehidupan sehari-hari. Sebagian besar partisipan mengatakan dulu mereka tidak melakukan ibadah dengan baik dan sekarang mereka belajar untuk memperbaiki ibadahnya. Seperti pernyataan partisipan yang berusia 26 tahun yang sudah 1 tahun menjalani hemodialisis berikut ini:

"Dulu saya termasuk orang yang sombong dan angkuh, dulu kan karena punya banyak uang jadi sholat ini kan gak penting kali, yang penting kerja, senang-senang, kerja yang menghasilkan uang lah, jadi lupa sama yang maha kuasa. Kalau sekarang sikitsikit lah belajar untuk rajin beribadah itu, dulu kan sholat bolong-bolong, dulu ada waktu untuk sholat saya males dan saya bawa tidur aja, sekarang saya merutinkan sholat, waktunya sholat, saya sholat. Sholat subuh saya usahain ke mesjid dan benerbener berusaha sholat tepat waktu. Sekarang saya sering dengerin ceramah di mesjid dari maghrib sampe isya selalu mesjid" [P2]

Kebutuhan spiritual pada pasien yang menjalani hemodialisis meliputi menguatkan hubungan dengan Tuhan, diri sendiri dan orang lain. Dukungan dari lingkungan sekitar partisipan akan membantu partisipan menghadapi proses penyakitnya. Seluruh partisipan mengungkapkan mereka mendapatkan dukungan dari orang-orang terdekatnya seperti keluarga, pasangan hidup, 
Fitri Mailani: Pengalaman Spiritualitas pada Pasien Penyakit Ginjal Kronis

dan teman-teman terdekat. Dukungan yang sangat berarti diperoleh dari keluarga dalam hal ini adalah pasangan hidup dan orang tua. Seperti pernyataan responden berjenis kelamin perempuan yang berumur 52 tahun berikut ini:

"Dukungan yang keluarga berikan sangat berharga sekali buat saya, mereka lah yang menasehati awak untuk sabar menghadapi semua ini, tapi memang orang itu bagus semua, sodara-sodara saya itu merangkul saya semua gak ada istilahnya dibiarkan”. Suami saya sering nelpon dan nanyakan saya udah makan, udah minum obat atau belum meskipun dia jauh.” [P1]

Sebagian besar partisipan mempunyai harapan besar untuk sembuh dan berharap Tuhan memberi mukjizat. Partisipan berharap bisa kembali bekerja seperti dulu dan dapat beraktivitas seperti biasanya sehingga dapat membantu perekonomian keluarga dan menyekolahkan anak-anak. Harapan responden juga ditunjukkan dengan mencoba pengobatan non medis, dan selalu berdoa agar diberi kesembuhan. Seperti pernyataan berikut ini:

“...dan terus berusaha kalau sembuh ya sembuh yang penting kita tidak pasrah dirumah tapi tetap berobat kerumah sakit, ya kan?.” "Kadang-kadang disuruh minum ini, minum ini, dicoba juga misalnya obat-obat kampung lah, tapi yang gak ada efeknya lah. Misalnya minum air ini lah (menunjukkan botol minum) ternyata setelah minum ini doyan makan" [P1]

"Setiap sholat saya selalu berdoa ya Allah sembuhkan lah penyakitku ini, kalau memang berkenan, karena anak ku masih dua lagi ya harus dididik, ya mudah-mudahan di denger doa awak." [P1]

...."saya berdoa disembuhkan penyakit saya dan memohon datangkan mukzijat itu ya Allah"...[P3]

Seluruh pasrtisipan mengungkapkan sekarang sudah bisa menerima dengan ikhlas penyakit yang diderita nya. Meskipun diawal menjalani hemodialisis partisipan sempat menolak, sedih dan tidak bisa menerima kondisi nya, namun seiring berjalannya waktu partisipan bisa menerima dengan ikhlas dan menganggap sakit yang diderita sebagai cobaan dari Tuhan. Partisipan yang diwawancara sudah menjalani hemodialisis dalam rentang 4 bulan-10 tahun sehingga sudah berada pada fase menerima kondisi nya dengan ikhlas, terlihat dari pernyataan responden seperti berikut ini:

"sekarang ya mau gimana lagi, saya lebih tenang dan mengangggap ini ujian, ntah ujian atau cobaan, udah dikasih yang kayak gini ya mau gimana lagi, ya diterima aja lah, masak Allah mau kita tentang”. Sekarang lebih tenang dan pasrah saja saya"[P2]

..."Ooooo..mungkin ini tuhan memberi cobaan, aku berpikir Tuhan tidak akan memberi cobaan di luar kemampuan ku, pasti Tuhan menganggap aku mampu, makanya aku diberi seperti ini" [P4]

\section{Pembahasan}

Spiritualitas merupakan bagian yang tidak terlepaskan dari kualitas hidup individu. Terlepas dari penyakit yang diderita, teknologi yang dikembangkan, atau terapi yang digunakan, model bio-psiko-sosialspiritual menyediakan petunjuk secara keseluruhan dalam merawat pasien dan memperoleh kesehatan yang sesungguhnya (Dossey, 2005). Banyak peneliti juga berpendapat bahwa masalah spiritual merupakan masalah yang sangat penting bagi pasien yang menderita penyakit kronik yang mengancam jiwa, untuk itu perlu pendekatan dengan model biopsikososial-spiritual dalam merawat pasien. Spiritualitas merupakan dimensi penting yang harus diperhatikan dalam penilaian kualitas hidup karena gangguan spiritualitas akan menyebabkan gangguan berat secara psikologis termasuk keinginan bunuh diri (Bele dkk., 2012).

Penelitian ini menggali spiritualitas pada pasien penyakit ginjal kronik yang menjalani hemodialisis. Data didapat melalui wawancara dengan responden, sehingga didapat beberapa tema yaitu mendekatkan diri kepada Tuhan, dukungan dari orang terdekat, mempunyai harapan besar untuk sembuh, dan menerima dengan ikhlas penyakit yang diderita. 
Fitri Mailani: Pengalaman Spiritualitas pada Pasien Penyakit Ginjal Kronis

Mendekatkan diri kepada Tuhan. Hal yang dirasakan oleh sebagian besar partisipan dalam kehidupan spiritualnya adalah mendekatkan diri kepada Tuhan, seperti dengan rajin beribadah, memperdalam ilmu agama, dan memperbaiki kualitas ibadah dalam kehidupan sehari-hari. Sebagian besar partisipan mengatakan dulu mereka tidak melakukan ibadah dengan baik dan sekarang mereka belajar untuk memperbaiki ibadahnya. Hasil penelitian ini menunjukkan bahwa seluruh partisipan merasa lebih dekat dengan Tuhan setelah menjalani hemodialisis. Sejalan dengan yang dikemukakan oleh Taylor, Lilis dan Lemone (2006) agama bisa merupakan bagian dari spiritual, dan memiliki dua komponen yaitu orientasi terhadap keagamaan dan terhadap eksistensi. Sebagian besar responden berusaha memperbaiki hubungan nya dengan Tuhan setelah didiagnosa menderita penyakit ginjal kronik dan menjalani hemodialisis.

Dossey (2005) menyatakan bahwa hubungan manusia dengan sang pencipta (Tuhan) merupakan elemen pertama dari spiritualitas. Lebih mendekatkan diri kepada Tuhan merupakan strategi koping yang paling sering digunakan oleh pasien untuk mengatasi stress karena penyakit yang dideritanya. Hal ini sejalan dengan penelitian Novalia (2011) tentang koping yang digunakan pada pasien penyakit ginjal kronik yang menjalani hemodialisis yang menyatakan bahwa 85,4\% responden menggunakan strategi koping spiritual dengan berdoa dan mendekatkan diri kepada Tuhan.

Ketika penyakit menyerang seseorang, kekuatan spiritual dapat membantunya ke arah penyembuhan atau pada perkembangan kebutuhan dan perhatian spiritual. Kekuatan spiritualitas seseorang dapat menjadi faktor penting dalam cara menghadapi perubahan yang diakibatkan oleh penyakit kronis (Potter \& Perry, 2005).

Dukungan dari orang terdekat. Salah satu elemen spiritualitas menurut Dossey (2005) yaitu keterhubungan dengan orang lain. Seluruh responden mengungkapkan mereka mendapatkan dukungan dari orang-orang terdekatnya seperti keluarga, pasangan hidup, dan teman-teman terdekat. Dukungan yang diberikan berupa dukungan fisik, emosional, dan keuangan. Komponen belonging dalam quality of life model meliputi social belonging terdiri dari keintiman hubungan dengan orang lain, keluarga, teman dan rekan kerja. Sedangkan untuk community belonging yaitu keinginan untuk terlibat dalam pelayanan sosial dan aktivitas sosial (University of Taronto, 2010).

Walton (2007) menyatakan dalam penelitiannya bahwa spiritualitas juga tidak terlepas dari keterhubungan dan dukungan dari keluarga. Keluarga juga merupakan sumber utama harapan bagi pasien yang menjalani hemodialisis, baik dari orang tua, suami dan keluarga besar (Weil, 2000). Pasien yang menjalani hemodialisis juga membutuhkan dukungan dari lingkungan sosialnya dalam menjalani kehidupan sehari-hari. Sejalan dengan penelitian Novalia (2011) yang mengatakan strategi koping lainnya selain spiritualitas yang membantu pasien untuk melakukan koping adaptif adalah dukungan sosial. Dukungan sosial merupakan sumber daya eksternal utama dalam menghadapi masalah dan merupakan salah satu faktor yang menentukan kemampuan seseorang untuk beradaptasi terhadap masalah yang dihadapinya (Potter \& Perry, 2005).

Dukungan sosial membuat seseorang merasa bahwa dirinya diperhatikan, dicintai, dihargai dan akan meningkatkan kepribadian mandiri dari individu tersebut. Dukungan sosial bisa didapat dari keluarga, lingkungan dan tim kesehatan. Dukungan dari orang lain di luar keluarga juga memberikan pengaruh positif pada pasien. Responden penelitian ini sebagian besar suku batak dengan hubungan kekerabatan sangat tinggi. Apabila ada orang yang mengalami kemalangan atau sakit maka kerabat akan datang silih berganti untuk memberi penghiburan kepada orang yang mengalami kemalangan atau sakit tersebut (Sudiharto, 2007). Dukungan ini memperlihatkan kepedulian dan kasih sayang bagi pasien sehingga sangat berarti baginya dalam melakukan koping yang adaptif dalam menghadapi penyakitnya dan menjalani hemodialisa. Faktor-faktor yang meningkatkan harapan pada pasien yang menjalani hemodialisis adalah pasien dapat melakukan aktivitas bersama-sama dengan keluarga dan teman-teman dan perasaan dibutuhkan atau perasaan berguna untuk orang lain (Weil, 2000). 
Fitri Mailani: Pengalaman Spiritualitas pada Pasien Penyakit Ginjal Kronis

Mempunyai harapan besar untuk sembuh. Sebagian besar partisipan mempunyai harapan besar untuk sembuh dan berharap Tuhan memberi mukjizat. Partisipan berharap bisa kembali bekerja seperti dulu dan dapat beraktivitas seperti biasanya sehingga dapat membantu perekonomian keluarga dan menyekolahkan anak-anak. Harapan responden juga ditunjukkan dengan mencoba pengobatan non medis, dan selalu berdoa agar diberi kesembuhan. Meskipun ada beberapa partisipan menganggap itu suatu hal yang mustahil, tapi mereka percaya akan mukjizat yang dimiliki Tuhan. Harapan yang tinggi akan memotivasi partisipan untuk menjalani kehidupannya ke depan diungkapkan secara bervariasi oleh partisipan dengan keinginan untuk terus berkarya dalam hal ini bekerja lagi atau membangun kembali kehidupan keluarganya, dan memanfaatkan kesempatan hidup yang diberikan Tuhan. Sumber harapan pada pasien yang menjalani hemodialisis adalah kepercayaan kepada Tuhan, dukungan dari keluarga dan lingkungan sekitar (Weil, 2000). Spiritualitas yang baik juga ditunjukkan dengan semangat untuk sembuh (Walton, 2007).

Menerima dengan ikhlas penyakit yang diderita. Seluruh responden juga mengungkapkan saat ini sudah bisa menerima dengan ikhlas penyakit yang dideritanya. Meskipun diawal menjalani hemodialisis responden sempat menolak, sedih dan tidak bisa menerima kondisi nya, namun seiring berjalannya waktu responden bisa menerima dengan ikhlas dan menganggap sakit yang diderita sebagai cobaan dari Tuhan. Responden yang diwawancara sudah menjalani hemodialisis dalam rentang 4 bulan-10 tahun sehingga sudah berada pada fase menerima kondisi nya dengan ikhlas. Sebagian responden mengatakan bahwa dengan menerima ikhlas penyakit yang dideritanya mereka merasa lebih tenang menjalani hidupnya.

Keikhlasan menerima penyakit yang diderita berbanding lurus dengan usaha mendekatkan diri dengan Tuhan. Sebagian partisipan mencoba mencari hikmah dari penyakit yang diderita nya, dan menganggap Tuhan tidak akan memberi cobaan diluar kemampuan umatnya. Hal itu lah yang membuat sebagian besar partisipan kuat dan semangat menjalani pengobatannya. Keikhlasan menerima kondisi dapat menyembuhkan luka jiwa pasien akibat kejenuhan dalam menjalani hemodialisis (Walton, 2007).

\section{Simpulan}

Hasil wawancara mendalam dengan partisipan didapatkan empat tema dalam mendeskripsikan spiritualitas yaitu: mendekatkan diri kepada Tuhan seperti rajin beribadah, memperdalam ilmu agama, dan memperbaiki kualitas ibadah dalam kehidupan sehari-hari. Dukungan dari orang terdekat, seperti dukungan dari keluarga, pasangan hidup, dan teman-teman terdekat. Mempunyai harapan besar untuk sembuh, seperti mencoba pengobatan non medis, yakin dengan mukjizat dan selalu berdoa agar diberi kesembuhan. Menerima dengan ikhlas penyakit yang diderita, seperti menerima penyakit sebagai bagian dari cobaan dari Tuhan. Hal ini menunjukkan bahwa pasien yang menjalani hemodialisis menggunakan pendekatan spiritualitas sebagai koping untuk menghadapi penyakit terminal yang dideritanya. Kedekatan dengan Tuhan, dukungan dari keluarga dan lingkungan menjadi penguatan dan meningkatkan motivasi pasien untuk sembuh. Untuk itu sangat penting bagi perawat dan keluarga melakukan pendekatan secara spiritualitas kepada pasien dan memberi dukungan untuk meningkatkan kualitas hidup pasien.

Perawat yang bertugas di ruang hemodialisa hendaknya membuat program yang mendukung kegiatan spiritualitas secara berkelompok sesuai dengan kepercayaan masing-masing pasien (support group). Perawat diharapkan mampu memberikan asuhan keperawatan dengan pendekatan spiritual (spiritual care) dan secara holistic. Perawat juga hendaknya dapat memfasilitasi pasien yang menjalani hemodialisis untuk melakukan kegiatan yang dapat meningkatkan semangat dan motivasi pasien. Dukungan keluarga akan sangat berarti dalam meningkatkan kualitas hidup, untuk itu partisipasi keluarga juga sangat dibutuhkan. 
Fitri Mailani: Pengalaman Spiritualitas pada Pasien Penyakit Ginjal Kronis

\section{Daftar Pustaka}

Alligood, M.R. \& Tomey, A.N. (2006). Nursing Theorist and Their Work,. 6th Edition. ST. Louis: Mosby Elsevier, Inc.

Bele, S., Bodhare, T., Mudgalkar, N., Saraf, A., Valsangkar, S., (2012). Health related quality of life and existential concern among patients with end stage renal disease. Indian Journal of Palliative Care, 18(2), 103-108. DOI 10.4103/0973-1075.100824.

Black, J.M., \& Hawks, J.H. (2009). Medical surgical nursing; clinical management for positive outcome. 8th edition. Philadelphia: W.B. Sounders Company.

Colaizzi, P. (1978). Psychological research as the phenomenologist's view it. In R. Vale \& M. King (Eds.), Existential-phenomenological alternatives for psychology (pp. 48-71). New York: Oxford University Press.

Dossey, B., M., Keegan, Lynn, \& Guzzetta, C. (2005). Holistic nursing a handbook for practice. United States of America: Jones Barlett Publishers.

Hawari, D. 2002. Dimensi Religi dalam Praktek Psikiatri dan psikologi. Jakarta: FKUI.

Headley, C.M \& Wall, B. (2000). Advanced practice nurses: Role in the hemodialysis unit. Nephrology Nursing Journal, 27. 177-187.

Ignatavicius, D. G. \& Workman, M.L. (2009). Medical Surgical Nursing: Patient-centered collaborative care. United States America: Sounders Elsevier.
Lincoln \& Guba dalam Sugiono. (2005). Memahami Penelitian Kualitatif. Bandung: Alfabeta.

Namawi, Q.(2013).Populasi Penderita Gagal Ginjal Terus Meningkat di 2013. http://health. okezone.com/read/2013/06/28/482/829210/ redirect diunduh pada tanggal 22 Oktober 2013.

Novalia, E.(2011). Koping pasien gagal ginjal kronis yang menjalani hemodialisa di RSUP HAM Medan. Diakses dari http://repository. usu.ac.id/handle/123456789/24973

Potter, P.A., \& Perry, A.G. (2005). Fundamental of nursing concept, process and practice. 4th edition. St Louis: Mosby Company.

Streubert, H.J, \& Carpenter, D.,R. (2011). Qualitatif Research in Nursing: Advancing the Humanistic Imperative, 2nd Ed. Philadelpia. Lippincott Williams \& Wilkins.

Sudiharto. (2007). Asuhan Keperawatan keluarga dengan pendekatan keperawatan transkultural. Jakarta: EGC.

Taylor, C., Lilis, C., \& Lemone, P. (2006). Fundamental of Nursing: the art and science of nursing care 5th Ed. Philadelphia: Lipincott.

Walton, J. (2007). Prayer Warriors: A grounded theory study of american indians receiving hemodialysis. Nephrology Nursing Journal, 34 (4), 377-389.

Weil, C., M. (2000). Exploring hope in patients with end stage renal disease on chronic hemodialysis. Nephrology Nursing Journal, 27(2), 219-224. 